\title{
Sansho Intake Modulates Ileum Activity in Stress-loaded Rats
}

\author{
Mari Kimoto ${ }^{1}$, Jorge L. Zeredo ${ }^{3,4}$, Masato S. Ota ${ }^{2}$, Zenro Nihei ${ }^{4}$, Kazuo Toda ${ }^{1,4,}$ * \\ ${ }^{1}$ Physiological Laboratories, Japan Women's University, Tokyo, Japan \\ ${ }^{2}$ Laboratory of Biochemistry and Food Biology, Japan Women's University, Tokyo, Japan \\ ${ }^{3}$ Graduate Program in Health Science and Technology, University of Brasilia, Brasilia, Brazil \\ ${ }^{4}$ Integrative Sensory Physiology, Graduate School of Biomedical Sciences, Nagasaki University, Nagasaki, Japan
}

Email address:

k-toda@nagasaki-u.ac.jp (K. Toda)

\section{To cite this article:}

Mari Kimoto, Jorge L. Zeredo, Masato S. Ota, Zenro Nihei, Kazuo Toda. Sansho Intake Modulates Ileum Activity in Stress-loaded Rats. Journal of Food and Nutrition Sciences. Special Issue: Effects of Foods on Gastrointestinal, Metabolic and Immunological Function. Vol. 3, No. 3-1, 2015, pp. 9-12. doi: 10.11648/j.jfns.s.2015030301.13

\begin{abstract}
Sansho (Japanese pepper) is a common spice widely used in Japanese cuisine. In addition, it is also an important component in Kampo medicine, such as in Daiken Chuto, which stimulates gastrointestinal motility and improves postoperative ileus. On the other hand, we previously reported that gravity stress loading produce negative effects on ileal movements. In the present study, we report changes in ileal motility after gravity-stress with and without Sansho intake in male and female rats. Ileal movements were activated by topical Acetylcholine (Ach) application, and maximum amplitudes (MA) of the evoked contraction were compared. Clear tonic patterns were observed in the ileal motility after Ach application. After short-term stress, there were no significant differences in MA between control and Sansho-intake groups in both sexes. However, after long-term stress-loading, significant enhancement of MA was observed in Sansho-intake group in males, but not in females. The present study showed that SAN affected Ach-induced ileal motility in the male, but not in the female after long-term stress loading, indicating sex differences in effects of Sansho intake. It is suggested that Sansho is more effective in males than in females to decrease negative stress response.
\end{abstract}

Keywords: Sansho (Japanese Pepper), Ileum, Stress, Motility, Sex Difference, Rat

\section{Introduction}

Sansho (Japanese pepper) is a common spice widely used in Japanese cuisine [1-3]. As a special interest, bioactivity of Japanese pepper has been found to originate from antioxidative, hepatic drug-metabolizing, tyrosinase inhibitory, and antimicrobial compounds [2]. A suppressive compound against trimethylamine, an amine known for the major unpleasant odor from fish, was sought in extracts of Japanese pepper fruit $[2,3]$. In addition, Japanese pepper is an ingredient of Kampo medicine in Japan, Korea, and China, such as "Daiken Chuto", which stimulates gastrointestinal motility and improves postoperative symptoms in the ileus [4-6].

On the other hand, we previously reported that gravitystress produces negative effects on ileal movements $[7,8]$. There are sex differences in the functional changes of the ileum and colon after stress loading [8]. Therefore, it is possible that stress-induced malfunction in the gastrointestinal tract could be improved by Sansho intake. In the present study, we examined changes in ileal motility after gravity stress with and without Sansho intake, in male and female rats.

\section{Materials and Methods}

The methods described here follow the ethical guidelines and received approval from the Animal Welfare Committees of Japan Women's University and Nagasaki University.

Detailed methods were described in our previous paper [7]. A total of one hundred and twenty-eight rats of both sexes (Wistar, SPF, body weight 220-321 g) received either standard rat chow (Oriental Yeast Co., Tokyo) or the same chow laced with $0.5 \%$ Sansho powder (Japanese Pharmacopoeia, $16^{\text {th }}$ Ed.). Four groups were divided: 1) Cont: no stress, no Sansho intake, 2) $S A N$ : no stress, Sansho intake, 3) STR: stress loading, no Sansho intake, 4) STRSAN: stress 
loading, Sansho intake. Each group consisted of 32 rats, both male and female. 3G-gravity stress (every day for $10 \mathrm{~min}$ ) was loaded by a centrifugal apparatus during 1 or 30 days.

Immediately after the stress loading at day 1 (short-) and day 30 (long-term), a $1 \mathrm{~cm}$-long section of the ileum was isolated under barbiturate anesthesia (Nembutal, $20 \mathrm{mg} / \mathrm{kg}$, i.p.), and fixed in a Magnus-type chamber filled with Tyrode solution. Ileal movements were activated by topical Acetylcholine (Ach, 10-5 mg/ml) application and maximum amplitudes (MA) of the evoked contraction were recorded.

One-way ANOVA was used to test differences in MA induced by Ach application among the four groups. Where significant interactions were found, post-hoc comparisons were done by the Bonferroni method. In all tests, $\alpha<0.05$ was considered statistically significant. All data are expressed as means \pm SEM.

\section{Results}

\subsection{Ach-induced Contraction}

As shown in Fig.1, Ach application induced a clear tonic contraction in the ileum. After Ach application, phasic or rhythmic contractions were absent, because tonic contractions were usually strong and long-lasting. Therefore, we measured MAs of this tonic ileal contraction, which showed the maximum force of the smooth muscle contraction.

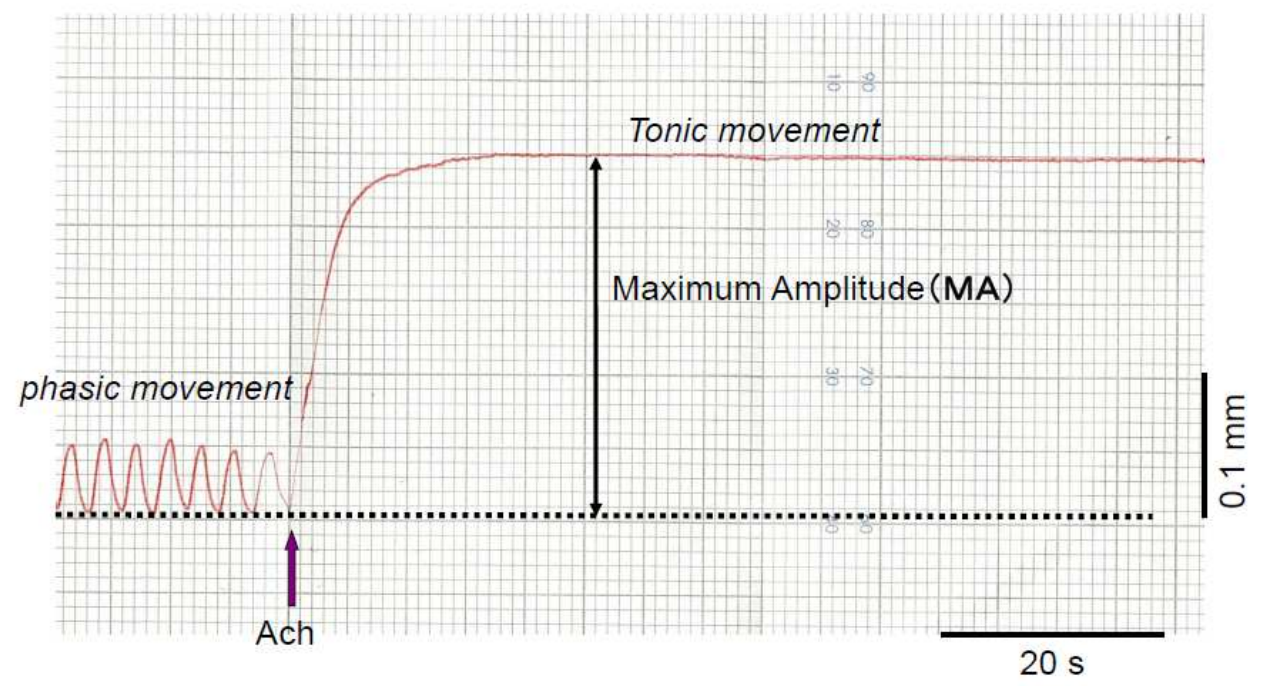

Fig. 1. Typical example of ileum contraction evoked by Ach. Rhythmic, phasic movement represents spontaneous ileal contractions. Ach application is followed by a strong, tonic contraction of the ileum.

\subsection{Short-term (1 day) Stress}

In Fig.2, a summary of the effects of Sansho intake and stress loadings are shown. In A, left to right, Cont, SAN, STR and STRSAN in male, and in B those in female are shown. After short-term stress, there were no significant differences in MA between all groups in both sexes.

\section{Day 1}
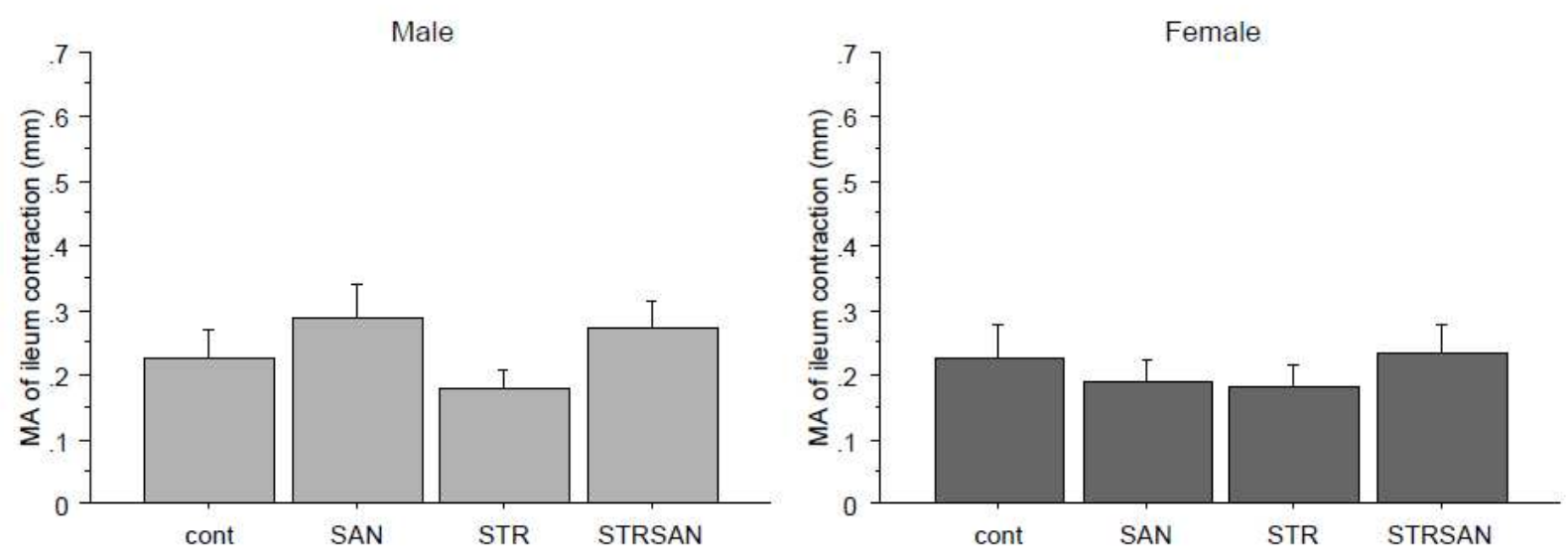

Fig. 2. Maximum amplitudes (MA) of ileal contraction in four experimental groups at day 1 in males (left) and females (right). Columns from left to right: 1) Cont: no stress, no Sansho intake, 2) SAN: no stress, Sansho intake, 3) STR: stress loading, no Sansho intake, and 4) STRSAN: stress loading, Sansho intake. Note that no significant differences were found among groups in both sexes. 


\subsection{Long-term (30 day) Stress}

In normal chow group, 30 day-stress loading, but not significant, seemed to inhibit ileal contraction in both sexes
(Fig.3. First and third column). In male, Sansho intake strongly enhanced Ach-induced contraction. In female, there were no significant differences among the four groups.

\section{Day 30}
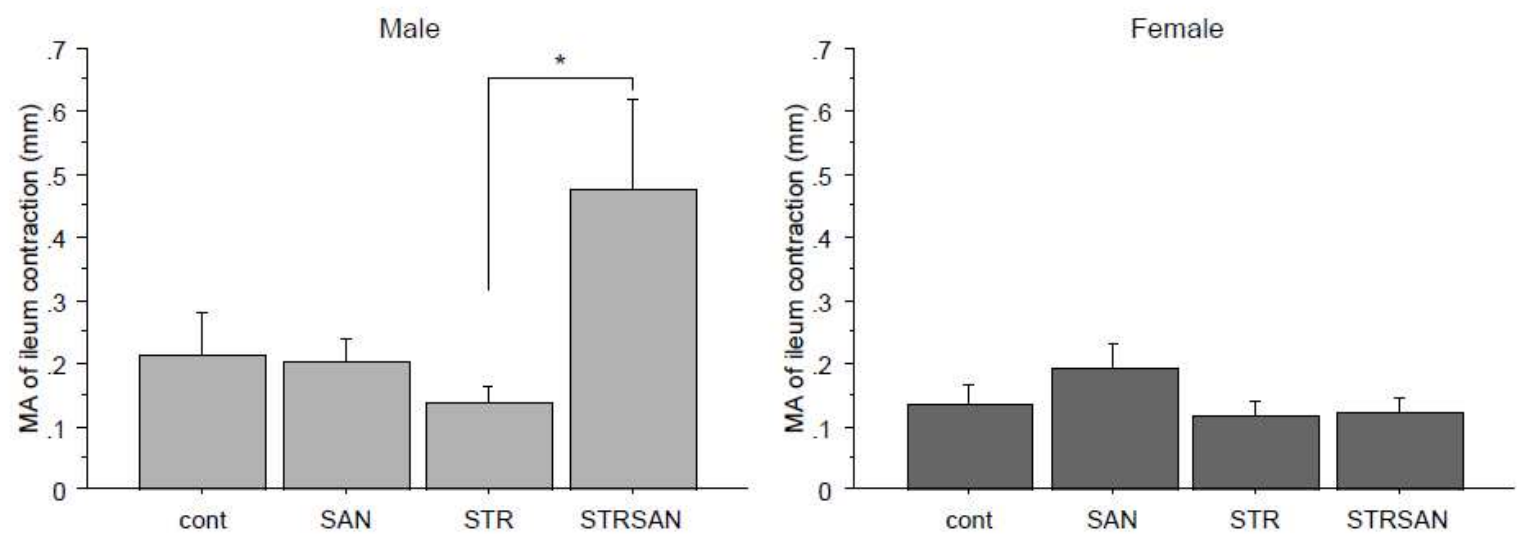

Fig .3. Maximum amplitudes (MA) of ileal contraction in four experimental groups at day 30 in male (left) and female (right). Columns from left to right: 1) Cont: no stress, no Sansho intake, 2) SAN: no stress, Sansho intake, 3) STR: stress loading, no Sansho intake, 4) STRSAN: stress loading, Sansho intake. Significant differences were found between STR and STRSAN in males.

\section{Discussion}

In the present study, sex differences were observed in the effects of Sansho intake under stress conditioning. In males, stress-inhibited ileal motility after long-term conditioning was well antagonized by Sansho intake. However, this effect was not observed in females.

It is generally accepted that there are sex differences in a majority of physiological or pathological phenomena, and especially in food intake [9-11]. In human studies, strong stress decreases body weight in both sexes; however, weak stress may sometimes decrease or increase body weight [1214]. In rats, our previous data showed that sex differences were observed in stress-induced ileal movements $[7,8]$. One of the possible explanations for sex differences is the endocrinological differences in the response to stress between male and female on various physiological functions, including digestion $[12,15]$.

Herbal medicine is frequently used in subliminal clinical treatment in oriental countries [16,17]. Sansho is widely used in various herbal medicinal drugs as a principal or accessory component [18]. Tokita et al. showed that Sanshool, a compound extracted from Sansho seed, can elicit gut smoothmuscle contraction in $7 \mathrm{w}$-old male BALB/c mice [19], which suggests that Sansho could improve digestive function by enhancing ileal motility. In the present study, long-term stress (30 days) suppressed ileal movements, and this suppression was well reversed by Sansho-intake in male rats. The mechanism of this observation may be due to the fact that Sansho-intake strongly activate TRPV1 and TRPA1 receptors in the proximal colon $[20,21]$.

In females, the present study indicated that Sansho intake caused no clear enhancement in ileum activity. Because short- or long-term stress did not significantly change ileal activities, female rats had stronger stress-resistance ability than males. Therefore, Sansho-intake effects on the ileal movement were not clear in female, suggesting that female rats did not need Sansho to reverse stress-induced digestive malfunction. In conclusion, it is shown that Sansho may be more effective in males than in females in reducing negative stress responses.

\section{Acknowledgement}

Supported by a Grant-in-Aid for Scientific Research (C) from JSPS .

\section{References}

[1] Jiang, L., Kubota, K. (2004) Differences in the volatile components and their odor characteristics of green and ripe fruits and dried pericarp of Japanese pepper (Xanthoxylum piperitum DC.). J Agric Food Chem. 52:197-203.

[2] Yamada, Y. (2009) Suppressive Compounds from Japanese Pepper (Zanthoxylum piperitum) against the Fishy Trimethylamine Odor. J. Home Econ. Jpn. 60:723-726.

[3] Ono, H., Nishio, S., Tsurii, J., Kawamoto, T., Sonomoto, K., Nakayama ,J. (2014) Effects of Japanese pepper and red pepper on the microbial community during nukadoko fermentation. Biosci Microbiota Food Health. 34:1-9.

[4] Okada, K., Kawai, M., Hirono, S., Miyazawa, M., Shimizu, A., Kitahata, Y., Yamaue, H. (2015) Perioperative administration of Daikenchuto (TJ-100) reduces the postoperative paralytic ileus in patients with pancreaticoduodenectomy. Hepatogastroenterology.62:466-71. 
[5] Akamaru. Y., Takahashi, T., Nishida, T., Omori, T., Nishikawa, K., Mikata, S., Yamamura, N., Miyazak,i S., Noro, H., Takiguchi, S., Mori, M., Doki, Y. (2015) Effects of daikenchuto, a Japanese herb, on intestinal motility after total gastrectomy: a prospective randomized trial. J Gastrointest Surg. 2015 19:467-72.

[6] Endo, M., Hori, M., Ozaki, H., Oikawa, T., Hanawa, T. (2014) Daikenchuto, a traditional Japanese herbal medicine, ameliorates postoperative ileus by anti-inflammatory action through nicotinic acetylcholine receptors. J Gastroenterol. 49:1026-39.

[7] Kimoto, M, Zeredo J.L., Ota, M.S., Nihei, Z., Toda, K. (2014) Comparison of stress-induced modulation of smooth-muscle activity between ileum and colon in male rats. Auton Neurosci. 183:8-11.

[8] Kimoto, M., Zeredo, J.L., Toda, K. (2012) Hypergravity conditioning on ileal movements in rats. Aviat Space Environ Med. 83:483-487.

[9] Fukushima, A., Hagiwara, H., Fujioka, H., Kimura, F., Akema, T., Funabashi ,T. (2015). Sex differences in feeding behavior in rats: the relationship with neuronal activation in the hypothalamus. Front Neurosci. ;9: eCollection doi: 10.3389/fnins.2015.00088.

[10] Papier, K., Ahmed, F., Lee, P., Wiseman, J. (2015) Stress and dietary behaviour among first-year university students in Australia: sex differences. Nutrition. 31:324-330.

[11] Spaeth, A.M., Dinges, D.F., Goel, N.(2014) Sex and race differences in caloric intake during sleep restriction in healthy adults. Am J Clin Nutr. 100:559-566.

[12] McEwen, B. S. (2011). Stress, sex and neural adaptation to achanging environment: mechanisms of neuronal remodeling. Ann. N. Y. Acad. Sci. 1204 (Suppl): 38-59.
[13] Maniam, J., Morris, M. J. (2012). The link between stress and feeding behaviour. Neuropharmacol. 63:97-110.

[14] Yau, Y. H., Potenza, M. N. (2013). Stress and eating behaviors. Minerva Endocrinology 38:255-267.

[15] Lucassen, P. J., Pruessner, J., Sousa, N., Almeida, O. F., Van Dam, A. M., Rajkowska, G., Swaab, D. F., Czéh, B. (2014). Neuropathology of stress. Acta Neuropathol. 127:109-135.

[16] Keatonga, L., Hayesa, J., Moanea, S., Lehaneb, M., O'Dohertyc, S., Kingstond, R., Fureyb, A. (2014). The effect of simulated gastro-intestinal conditions on the antioxidant activity of herbal preparations made from native Irish hawthorn. J. Herbal Med. 4:127-133.

[17] Allisona, D. B., Fontaineb, K. R., Heshkaa, S., Mentorec, J. L. Heymsfieldc, S. B. (2001). Alternative treatments for weight loss: A critical review. Critical Reviews in Food Science and Nutrition. 41:1-28.

[18] Manabe, N., Camilleri, M., Rao, A., Wong, B.S., Burton, D., Busciglio, I. (2010) Effect of daikenchuto (TU-100) on gastrointestinal and colonic transit in humans. Am J Physiol Gastrointest Liver Physiol. 298:970-975

[19] Tokita, Y., Akiho, H., Nakamura, K., Ihara, E., Yamamoto, M. (2015) Contraction of gut smooth muscle cells assessed by fluorescence imaging. J Pharmacol Sci. 127:344-351.

[20] Koo, J.Y., Jang, Y., Cho, H., Lee, C.H., Jang, K.H., Chang, Y.H., Shin, J., Oh, U. (2007) Hydroxy-alpha-sanshool activates TRPV1 and TRPA1 in sensory neurons. Eur $\mathrm{J}$ Neurosci. 26:1139-1147.

[21] Kubota, K., Ohtake, N., Ohbuchi, K., Mase, A., Imamura, S., Sudo, Y., Miyano, K.,Yamamoto,M., Kono,T., Uezono, Y. (2015) Hydroxy- $\alpha$ sanshool induces colonic motor activity in rat proximal colon: a possible involvement of KCNK9. Am J Physiol Gastrointest Liver Physiol. 308(7): G579-G590. 